\title{
Equal opportunities: a necessity for quality in research
}

\section{SYBILLE KRUMMACHER}

In Germany, $6.8 \%$ of the male students who finished their biology

degree between 1977 and 1979 reached a "habilitation" within the ten following years (more exactly: 1986 to 1988). Only $0.8 \%$ of the women who finished their biology degree between 1977 and 1979 received a "habilitation" within the ten following years 1 . Habilitation is the German entry ticket to tenured professorship.

This means that, on the basis of the number of women finishing their basic degree at the end of the 1970s, we could have had eight times more women professors in biology at the end of the 1980s if their chances of development had been equal to that of the men. In other fields this factor varies -- from 6 in chemistry to 15 in pharmaceutical chemistry. This is a tremendous waste of intellectual potential. There are also now not enough women applicants for professorships or institute director positions, even though enough of them were in the starting positions 20 years ago.

The reasons for this situation are of course manifold and have been discussed extensively in the last years. One reason that might be specific to Germany is the awarding of multiple short-term contracts to young scientists, which involves relocation every $3 \geqslant 5$ years, often even beyond the age of 30 years, which makes it virtually impossible therefore to reconcile a scientific career with the establishment of a young family. This is why I am convinced that special programmes to increase the participation of women in science based on scholarships -- such as re-entry scholarships and special 2 habilitation scholarships for women -- cannot be more than a stopgap. They have been used extensively at German universities in recent years and although they have begun to show some effect -- an increase from $6.5 \%$ in 1992 to $9 \%$ in 1997 in all professorships -- they do not address one of the central issues: the need for a long-term perspective, especially at the time of the foundation of a young family.

This is why I am thrilled that my own institution, Research Centre Jülich, has taken a different approach and has launched its Tenure Track Programme for the Promotion of Women Scientists $?$. The basic idea follows the American tenure track concept, which outlines an academic career from postdoctoral researcher to a fixed-term professorship, culminating in a permanent contract. We use this concept to give women a long-term perspective for achieving top positions in science at an early stage in their careers. Each year, beginning in 1999, three outstanding female scientists will be offered job opportunities as a group leader, initially with 2-year fixed-term contracts. This starting phase will be used to integrate the scientist into the institute? sesearch programme and will enable her to develop her own working style. In the subsequent consolidation phase she will already be working on a permanent contract. During this phase she can expand and consolidate her research and personnel management experience so that she can qualify for leadership positions in science at the end of the 5-year programme.

But we know that this is not enough: we also have to change the boundary conditions, and in particular make the research centre a more family-friendly working place. Efforts are therefore now being concentrated on establishing and maintaining a child care facility at Research Centre Jülich as a model project within the framework of a private public partnership. This is a joint initiative by the board of directors of the Research Centre and the registered association of the parents initiative $>$ Kleine Fuechse e.V. $>$ Little Foxes?). The model envisages that the non-profit association, already 
recognized by the youth welfare committee of the local authorities as an independent youth welfare organization, should take over responsibility for the day care centre. The Research Centre will make available accommodation suitable for conversion into a day care centre and will grant the association the right to use the rooms in accordance with legal provisions. Furthermore, the Research Centre will support the association as much as possible in organizing child care services, particularly in realizing the concept of introducing children to science and technology through appropriate games and activities.

Since last October the staff of Research Centre Jülich and the people in the surrounding area have already been able to enjoy the first fruits of this partnership: all-day holiday activities for primary school children with professional supervision were held for the first time in the 1998 autumn holidays and use was also made of the Research Centre s scientific environment for the activities of the programme. The children were introduced to simple tools and concerned themselves with the topic of energy and solar energy -- one of the Research Centre $s$ research priorities. At this early age we could not observe any differences between girls and boys in their attitudes towards these subjects and activities. They were simply thrilled by the attractions offered, and it is hoped that these children, especially the girls, will have a more natural and self-assured approach to science when they grow up.

Research Centre Jülich does not consider the promotion of women in science as a social welfare programme for the handicapped, but as a necessity in its drive to exploit the potential of the scientific work force for research and innovation in the interest of competition, quality management and differentiation. The two examples described above are part of a programme of five lines of action whose interaction represents a basic prerequisite for realizing equality of opportunity and that in the long term will lead to a greater presence of women in top scientific and administrative positions.

\section{Sybille Krummacher}

Research Centre Jülich, Jülich, Germany

\section{References}

1. Nanny Wermuth: "Frauen an Hochschulen: Statistische Daten zu den Karrierechancen". K.H. Bock Verlag, 1992. ISBN 3-87066714-1.

Nature ㄷ Macmillan Publishers Ltd 1999 Registered No. 785998 England. 